\title{
POSTINFECTIOUS AND ISOLATED PARALYSIS OF THE SERRATUS MAGNUS.
}

\author{
By AUgUSTE TOURNAY, Paris, and WALTER \\ M. KRAUS, New York.
}

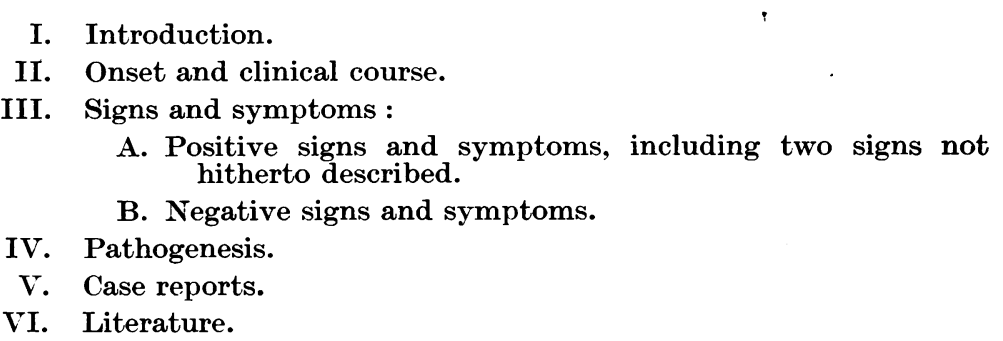

\section{I.-INTRODUCTION.}

REPORTS of isolated paralysis of the serratus magnus following influenzalike infections are quite rare. Indeed, reports of postinfectious paralysis of any origin are not numerous. Of the seventeen cases of isolated paralysis from all causes gathered, in $\mathbf{1 8 9 9}$, by Souques and Castaigne, ${ }^{15}$ and including their own, two followed typhoid fever (Bäumler, ${ }^{6}$ Souques and Castaigne), and one puerperal infection (Weber ${ }^{7}$ ). Claude and Descomps ${ }^{16}$ reported in 1907 a case of unknown infectious origin; Bertrand and Chailly, ${ }^{17}$ in 1909 , one following measles. Of a total of 12,000 cases, Remak ${ }^{8}$ found but three of isolated paralysis of any type.

In 1879, Bernhardt ${ }^{5}$ reported a case following an influenzal attack. Rad 12 published another in 1898. A third was reported by Guillain and Libert ${ }^{19}$ in 1920. Thus, as far as we have been able to find, but three cases of such origin have been reported to date.

\section{II.-ONSET AND CLINICAL COURSE.}

The onset of the paralysis in our case, ${ }^{*}$ as well as in those of Bernhardt, ${ }^{5}$ Rad ${ }^{12}$ and Guillain and Libert, ${ }^{19}$ was associated with a typical attack of influenza. Signs of bronchopneumonia are sometimes associated with these cases of serratus paralysis, as occurred in Souques and Castaigne's case (typhoid fever) and one of ours. In one of these the bronchopneumonia was rightsided; in the other leftsided. Whether this bore any relation to the paralysis, which occurred on the same side,

\footnotetext{
* See Section V. for case reports.
} 
seems open to question, since most rightsided bronchopneumonias are not associated with serratus paralysis, and since all but one of the reported cases of paralysis, that of Bernhardt (1879), occurred on the right side.

Several days or weeks after onset, and after the patient has recovered from his acute infection, a severe pain is felt below the axilla, in the chest. Pain is also present about the shoulder, in the supraclavicular and suprascapular regions. The patient notices difficulty in the use of the arm, and winging of the scapula may be observed by others. The pain gradually subsides, the winging increases. Tenderness over the long respiratory nerve of Bell is present

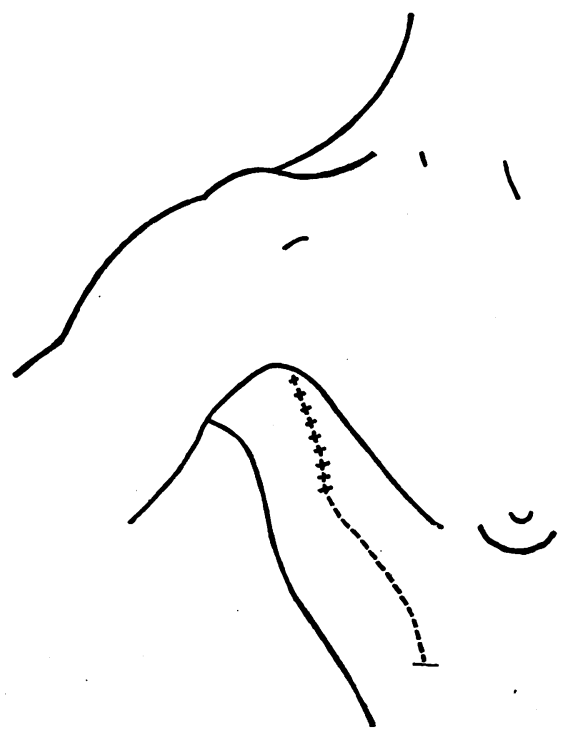

Fig. 1.-Case 3. Sketch taken four months after onset. View of the axilla. The line indicates that part of the midaxillary line pressure on which evokes exquisite tenderness over the long respiratory nerve of Bell. The crosses $(++++)$ indicate that part which was spontaneously painful. from the beginning, and persists for months. The most tender point is found in the midaxillary line in the fourth interspace (Fig. 1). It is normally a little tender, but in serratus paralysis it is exquisitely so, and in marked contrast to the unaffected side. There are no cutaneous sensory disorders and no reflex changes.

The course is long and the prognosis not favourable in most cases of isolated serratus paralysis of various origins.

\section{III.-SIGNS AND SYMPTOMS.}

Attention is at once attracted to serratus paralysis by two very striking signs: one the deformity due to winging of the scapula, the other the difficulty in lifting the arm above the horizontal. However, a methodical examination is necessary to show the various results of these signs, to reveal others, to make certain that the serratus alone is affected and that the trapezius, latissimus dorsi, and other muscles are not also weak, as frequently occurs in neuritis of the brachial plexus.

Leaving disorders of sensation, reflexes and electrical reactions aside, there are a considerable number of other signs, deformities or topographical displacements, which are made evident by requesting the patient to execute various movements with his arm, such as retraction, protraction and abduction of the arms, and shrugging of the shoulders. 


\section{A. Positive Signs and Symptoms.}

1. The pain and tenderness have already been mentioned above. Their localization is indicated in Fig. 1.

2. The reaction of degeneration is found quite regularly.

3. The patient cannot, as a rule, lift his arm above the horizontal (Fig. 3), and the movement of lifting is not as forceful as normally. Sometimes the arm may be lifted a few degrees above the horizontal. This has evoked considerable discussion (Bruns, ${ }^{10}$ Souques and Castaigne ${ }^{15}$ ). It depends, most probably, on the development of the middle portion of the trapezius (Souques and Castaigne).

4. The scapula is sometimes higher on the paralyzed side when the arms are pendent and at rest.

5. The affected shoulder is sometimes lower when the patient is at rest ; it is higher when the scapulæ are brought to the midline (Fig. 5).

6. The sternocleidomastoid and trapezius are more forcibly contracted on the paralyzed side when the arms are abducted (Fig. 6).

7. Deformity of the thorax was described by Souques. ${ }^{14}$ On the paralyzed side an S-shaped curve is formed (Figs. 3, 6, 8). This is apparent when the arms are at rest, abducted, protracted or elevated.

8. The axilla is not normal in form on the affected side. When the arms are abducted, the outline of the axilla is round rather than angular, as on the normal side (Fig. 6). This is really part of the S-curve of Souques.

9. Measurement of the chest shows that the affected side is smaller.

10. When the patient is asked to lift his shoulder forcibly, it is seen that the supraclavicular fossa on the affected side is both narrower and more perpendicular than on the unaffected side (Fig. 7). This sign was described by Guillain and Libert. ${ }^{19}$

11. The movement of lifting the arm produces winging of the scapula (Figs. 2, 3, 4, 8, 9). Forceful pushing against a wall evokes this to the maximum.

12. When the arms are carried forward, protracted, the sign of contraction of the lower part of the trapezius is shown ; abduction also brings this out (Figs. 3, 4, 6, 8). This sign was described by Souques and Castaigne. ${ }^{15}$ It consists of the appearance of two troughs, formed by the lowermost fibres of the unparalyzed trapezius, when the arm is protracted. One is medial to the contracting trapezius, and is long and narrow ; the other is lateral and is pyramidal in shape. When the arms are abducted, this trough formation is not so clearly defined, but the presence of the contracting trapezius is still easily seen (Fig. 6). This sign is extremely important, as exclusion of paralysis of the lowermost parts of the trapezius is otherwise difficult.

13. The normal relation of the vertebral border of the scapula to 


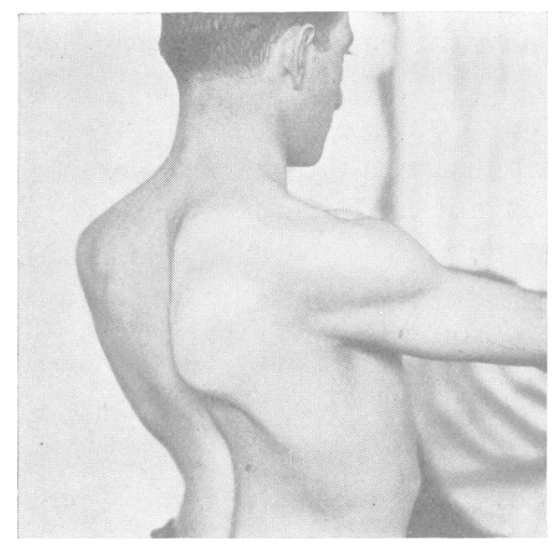

Fig. 2.-Case 1. Photographs taken two months after onset. (a) Winging of right scapula. (b) Normal outline of deltoid.

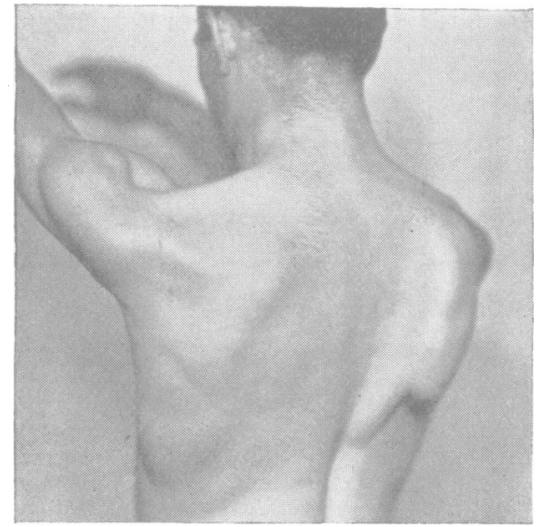

FIc. 4.-Case 1. (a) Winging. (b) Trapezius sign of Souques and Castaigne. (c) Right arm can be lifted somewhat above the horizontal.

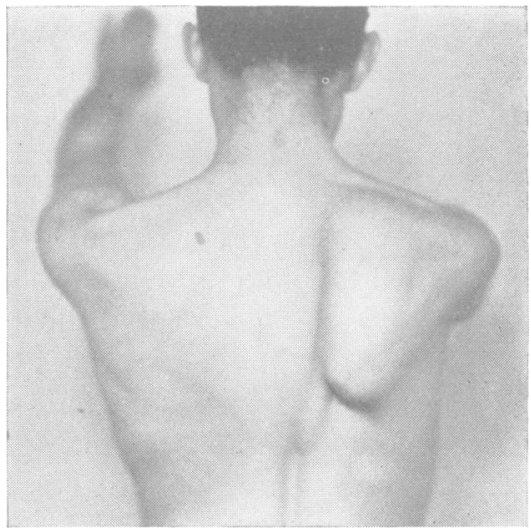

FIG. 3.-Case 1. (a) Inability to raise the right arm above the horizontal. (b) The S-curve of Souques is present to some degree. (c) Winging. (d) Trapezius sign of Souques and Castaigne: the lowermost fibres of the trapezius form a ridge medial to the scapula, and the two troughs described in the text are present. (e) The uppermost fibres of the trapezius are more forcibly contracted on the paralyzed side. ( $f$ ) The right scapula is nearer the vertebral column than the left.

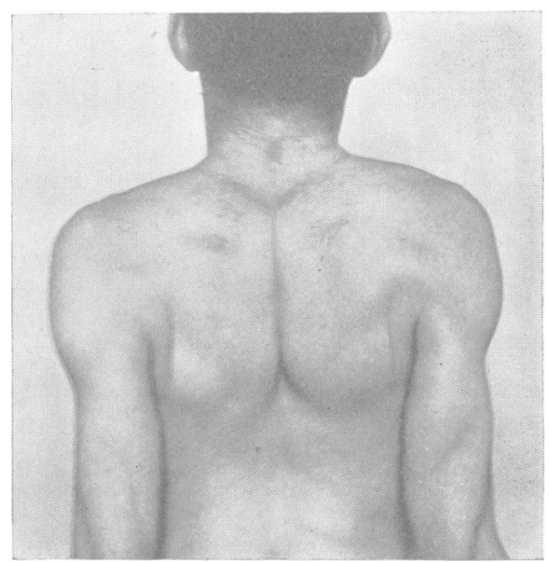

Fic. 5.-Case 1. To show normal action of the rhomboidei, elevation of the affected shoulder, and greater contraction of the trapezius on the right. 


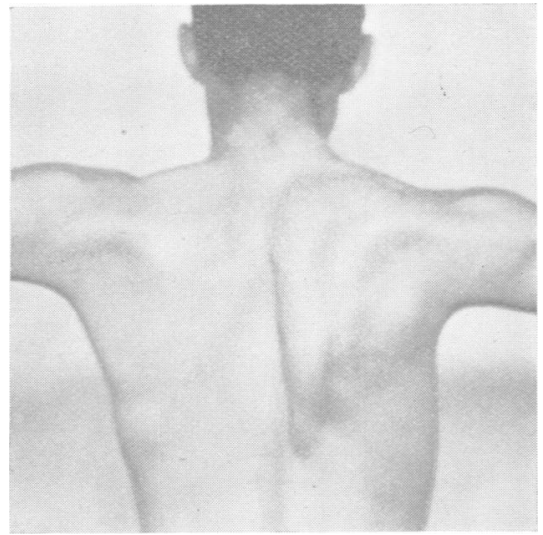

Figs. 6 (AND 6A).-Case 1. (a) Winging to some degree. (b) Trapezius sign of Souques and Castaigne. (c) The uppermost fibres of the trapezius are more forcibly contracted on the paralyzed side. (d) The scapula overlaps slightly the vertebral column. (e) The S-curve of Souques is very evident. $(f)$ The trapezius-deltoid line is longer on the affected side.

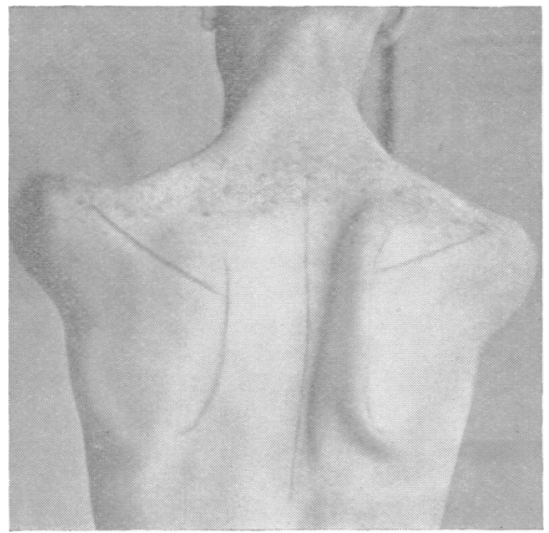

Fra. 8.-Case 2. Photograph taken two and a half months after onset. (a) Slight elevation of the right scapula. (b) Winging. (c) Trapezius sign of Souques and Castaigne. (d) Scapula nearer midline on the affected side.

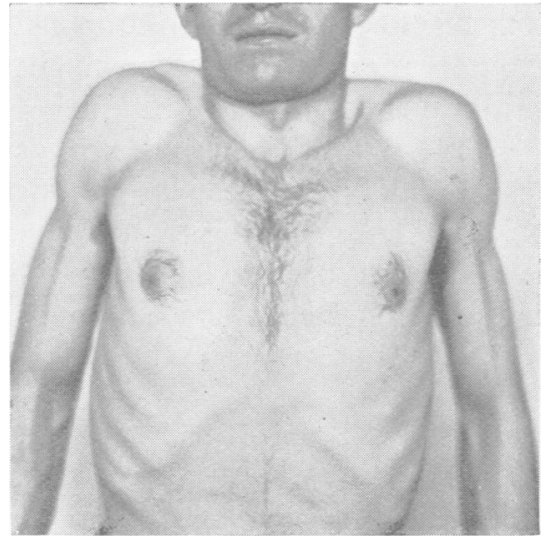

Figs. 7 (AND 7A).-Case 1. (a) Narrowing and perpendicular direction of the supraclavicular fossa on the patient's right (sign of Guillain and Libert). (b) Shortening of the sternocleidomastoid-deltoid line on the affected side. (c) Deltoids normal.

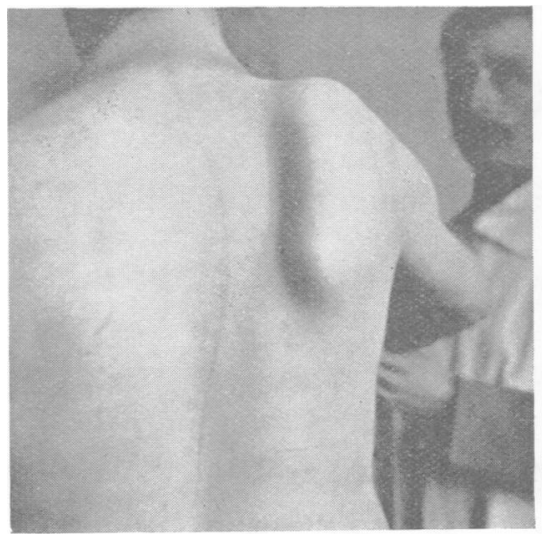

Fig. 9.-Case 3. Photograph taken four months after onset. (a) Elevation of the affected scapula. (b) Winging. (c) Scapula nearer midline on the affected side. (d) Scoliosis. 
the midline of the vertebral eolumn is altered. The scapula is nearer the midline. When the arms are abducted, it may overlap the medial line of the vertebral column (Fig. 6). This is a sign in differentiation from trapezius paralysis, since there the scapula is farther from the midline than normal (Souques and Duval ${ }^{13}$ ) (Fig. 10).

14. A mild degree of scoliosis is sometimes present (Fig. 9).

15. Besides these are two signs which have not been found recorded :

(a) Lengthening of the line between the deltoid and the trapezius is apparent on the affected side, when the patient is examined from behind with his arms abducted (Figs. 6, 6A).

(b) Shortening of the line between the deltoid and the sternocleido-

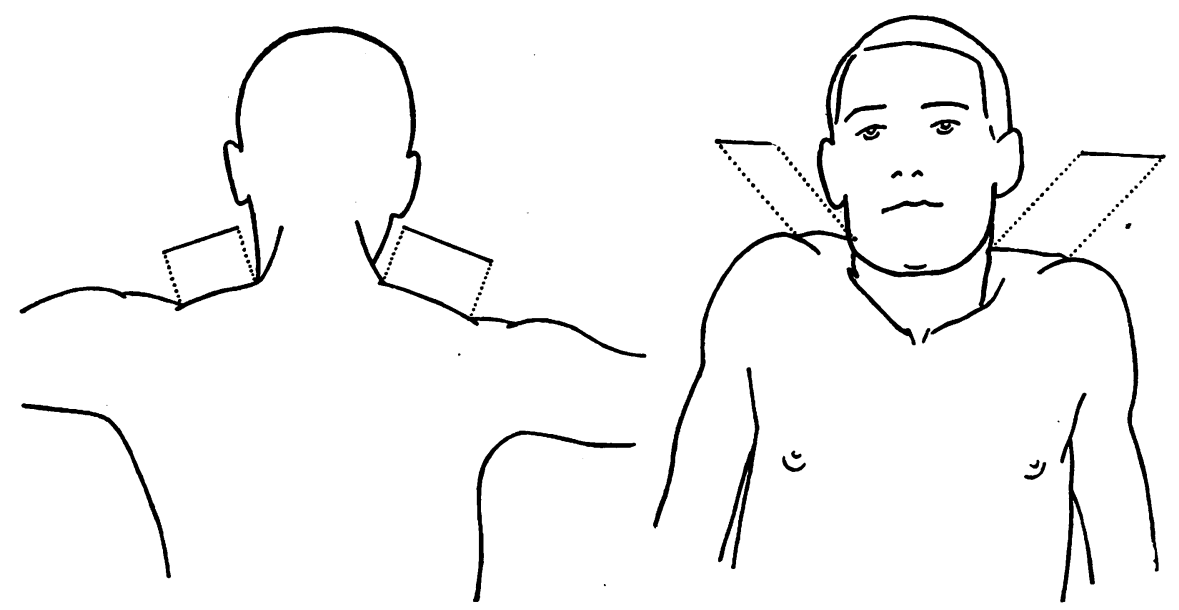

Fig. 6A.

Fig. $7_{\mathrm{A}}$.

mastoid is apparent antcriorly on the affected side when the patient is asked to shrug his shoulders, as in looking for the sign of Guillain and Libert (Figs. 7, 7A).

\section{B. Negative Signs and Symptoms.}

The negative signs which establish that the serratus magnus alone is paralyzed are equally important. The muscle is supplied by the fifth, sixth, and seventh cervical roots.

1. The biceps and triceps reflexes being normal indicate that the afferent and efferent pathways from $\mathrm{C} 5$ and $\mathrm{C} 6$ (biceps) and $\mathrm{C} 7$ (triceps) are unaffected.

2. The deltoid is seen to be normal in contour (Figs. 2, 5, 7) and in motor power.

3. The rhomboidei act normally in bringing the scapulæ together to the midline (Fig. 5). 
4. The lower part of the trapezius is found normal by the sign of Souques (the two troughs, Figs. 3, 4, 6, 8), and its upper part by the ability to elevate the shoulder. Furthermore, in combined serratus and trapezius paralysis, the vertebral border of the scapula is tilted obliquely, its upper portion being more lateral than its inferior portion. The scapula on the affected side is farther from the midline than on the unaffected side (Fig. 10). This is also seen in isolated trapezius paralysis (Souques and Duval).

5. The rotators act normally.

6. The pectorals are easily tested by making the patient push the examiner's hand laterally across the chest, the examiner in the meanwhile grasping the muscle with the other hand.

7. The latissimus dorsi can be tested by hooking a finger into the axilla under the muscle and asking the patient to cough. The tug of the muscle is readily felt. The two sides are compared for further proof.

8. The electrical reactions indicate that the above-mentioned muscles and the others in the shoulder region are normal.

9. The lack of sensory findings forms further proof.

10. There is no pain on pressure on the brachial plexus or its branches, except that to the serratus magnus.

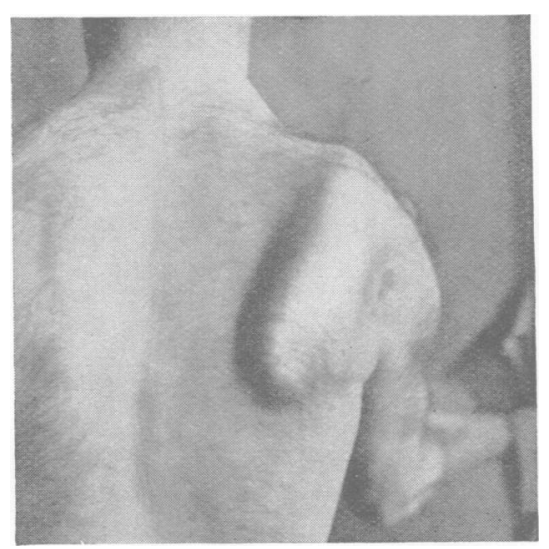

FIG. 10.-Photograph taken in a case of paralysis of the trapezius associated with paralysis of the serratus magnus, to show : (a) Winging. (b) Oblique position of the vertebral border. (c) Absence of sign of Souques and Castaigne. (d) The inferior angle of the scapula is farther from the median line on the affected side.

\section{IV.-PATHOGENESIS.}

The cases due to infection are, as we have noted, very rare. Measles, puerperal fever and typhoid fever cases have been reported, as well as the group described here, due to influenza. A few cases, as our case 3, have had infections of unknown or unproved etiology. Exposure to cold has been reported as a cause (Marchessaux, ${ }^{1}$ Busch ${ }^{2}$ ).

A relation to pleuropneumonia is suggested in some cases in view of the lymphatic drainage from the apical plcural lymph channels into the deep cervical glands about the brachial plexus. The rarity of the paralysis, however, in cases of bronchopneumonia leaves a certain scepticism as to this theory. In our case 1 the pneumonia was on the left side, the paralysis on the right. In case 2 the patient probably had a leftsided pleurisy, but the paralysis was on the right. 
The relation of the condition to the carrying of heavy weights on the shoulders and to excessive use of the arm is certain. The cases of Wiesner, ${ }^{3}$ Woodmann,4 Bernhardt, ${ }^{5}$ Buchmüller,9 Barreïro ${ }^{11}$ indicate this. The patient in case 1 of our series lifted heavy rolls of cloth daily. In such instances a rudimentary cervical rib or enlargement of the last cervical transverse process may be demonstrated, as in our case 3 , and undoubtedly plays a part.

We feel that no one factor alone is responsible. Carrying heavy weights plus the presence of a rudimentary cervical rib probably suffices to cause the paralysis. When infection is added, it presumably produces the paralysis by striking a 'locus minoris resistentia.'

\section{V.-CASE REPORTS.}

Case 1.-A young married man, age twenty-four, who had been working in a tailor's shop lifting heavy rolls of cloth daily, became ill in April, 1923, with an influenza-like infection associated with fever and congestion of the left lung. Within a few days the acute condition cleared up, but on rising from bed the patient felt a very severe pain in his right neck and shoulder. This pain was supraclavicular, and also over the posterior parts of the deltoid. He described it as 'terrific.' The pain abated somewhat, but continued through April and May. The patient was referred by his physician, Dr. Wm. Harris, in June. By that time he noticed a paralysis of some of the movements of the right arm, particularly the forward and upward movement. He could not lift his arm in front of him much beyond the horizontal. Urine and Wassermann test were negative.

On examination, signs of paralysis of the serratus magnus were confirmed by the electrical reactions. $X$-ray investigation showed increase in size of the transverse process of both cervical vertebra (see Figs. 2, 3, 4, 5, 6, 7).

Case 2.-An American officer, age twenty-four, was taken ill in March, 1918. After considerable exposure to cold and wet, great lack of sleep, lying in the water in the trenches, and general fatigue, he suddenly felt a severe pain in the left shoulder and chest. His pain was increased by forced respiration and also during normal respiration. He could not lie on the right side on account of the pain in the chest (pleurisy?). On March 27 weakness of the serratus magnus was noted. On April 1 the paralysis was found to be complete. Isolated paralysis of the serratus magnus was confirmed by electrical reactions (see Fig. 8).

Case 3.-H. G., a German prisoner, age twenty-five, had been wounded, in August, 1917, in the lower jaw. In the beginning of September, while prisoner in a French hospital and among many cases of influenza, he felt pain in the right supraclavicular and suprascapular regions. This had no relation to the wound. About a month later the pain became more severe and spread to the thorax in the subaxillary region. Up to this time he had felt only some discomfort in the right arm, but now noted some real weakness.

On examination in the beginning of January, 1918, signs of isolated 
paralysis of the serratus magnus, confirmed by the electrical reactions, were found (see Figs. 2, 9).

\section{VI.-REFERENCES.}

1 Marchessacx, Arch. gén. de méd., 1840, 313 (15).*

2 Busch, Deut. Arch. f. Klin. Chir., 1863, 39 (15).

3 Wiesser, Arch. f. klin. Med., 1869, vi, 95 (15).

4 Woodmax, Brit. Med. Jour., October 7 , 1875(15).

5 Bernhardt, Arch. f. klin. Med., 1879, 380 (15).

${ }^{6}$ BäUmLer, Deut. Arch. $f$. Klin. Med., 1880, 305 (15).

7 Weber, Dout. med. Woch., 1880, 277 (15).

8 ReMak, Berlin. Gesells. f. Psych. u. Nerv., December 12, 1892 (15).

9 Buchmǘlter, Inaug. Dissert., Frlangen, 1892 (15).

10 Bruss, Neurol. Centralbl., 1893, 34.

11 Barreiro, Thèse de Paris, 1895 (15).

12 RAD, Münch. med. Woch., 1898, 1145.

13 Souques and Deval, Nouv. Icon. Salp., 1898, No. 6.

14 Souques, Soc. méd. des hôp., October 21,1898 (15).

15 Souques and Castaigine, Nouv. Icon. Salp., 1899, No. 3.

16 Claude and Desconps, L'Encéphale, 1907, 28 (19).

17 Bertraxd and Chailix, Presse méd., 1909, 611 (19).

18 Guillain and Libert, Sioc. méd. des hôp., July 18, 1919) (19).

19 Guillais and Libert, Annales de méd., 1920, vii, 383.

* References cited by authors, but not read by us in the original, are indicated by bracketed numbers. These numbers refer to the sources of these references in this bibliography. 